\title{
CURRENT HARMONIC COMPENSATION AND POWER FACTOR IMPROVEMNT BY A NEW CONTROL ALGORITHM USING HYBRID ACTIVE POWER FILTER
}

\author{
Deepak sharma ${ }^{1}$, BSSPM Sharma ${ }^{2}$, V Siva Brahmaiah Rama ${ }^{3}$ \\ ${ }^{I}$ Mewar University, Electrical \& Electronics Division, Rajasthan India \\ ${ }^{2}$ Mewar University, Electrical \& Electronics Division, Rajasthan India \\ ${ }^{3}$ Mewar University, Electrical \& Electronics Division, Rajasthan India
}

\begin{abstract}
In this paper the current harmonic can be compensated by using the Shunt Active Power Filter, the Passive Power Filter and the combination of both. The system has the function of voltage stability, and harmonic suppression. The reference current can be calculated by using a new control algorithm by using three phase hybrid shunt Active power. An improved Control algorithm is proposed to improve the Performance of APF. The simulation results of the Non-linear systems have been carried out with MATLAB 7.6.
\end{abstract}

Index Terms: Three-phase active power filter, harmonic elimination, power factor correction, passive filter, control algorithm.

\section{INTRODUCTION}

The growing use of electronic equipment produces a large amount of harmonics in the power distribution systems because of non-sinusoidal currents consumed by non-linear loads. Some of the examples for non-linear loads are diode-rectifiers, thyristor converters, adjustable speed drives, furnaces, computer power supplies uninterruptible power supplies, etc. Even though these devices are economical, flexible and energy efficient, they may degrade power quality by creating harmonic currents and consuming excessive reactive power. The above phenomena can cause many problems such as resonance, excessive neural currents, low power factor etc. Harmonic distortion in power distribution systems can be suppressed using two approaches namely, passive and active powering. The passive filtering is the simplest conventional solution to mitigate the harmonic distortion. Although simple, the use passive elements do not always respond correctly to the dynamics of the power distribution systems. Over the years, these passive filters have developed to high level of sophistication. Some even tuned to bypass specific harmonic frequencies. Conventional passive filters consist of inductance, capacitance, and resistance elements configured and tuned to control the harmonics. The single tuned "notch" filter is the most common and economical type of passive filter. The notch filter is connected in shunt with the power distribution system and is series-tuned to present low impedance to a particular harmonic current. Thus, harmonic currents are diverted from their normal flow path through the filter. Another popular type of passive filter is the high-pass filter (HPF). Passive LC filters are generally used to reduce these problems, but they have many de-merits such as its being bulk and heavy, and its resonance, tuning problem, fixed compensation, noise, increased losses, etc. On the contrary, the APF can solve the aforementioned problems and is often used to compensate current harmonics and low power factor that is caused by non-linear loads. In an APF connection, it was roughly classified as in series (series APF) and in parallel (shunt APF). In this paper the combination of both passive power filter and Active power filter can be implemented to suppress the harmonics.

\section{CONFIGURATION OF THE SYSTEM}

Fig. 1 shows a proposed system consisting of a Shunt active power filter and Passive filter. The purpose of using this combined system is to reduce the harmonics effectively. The power factor also improved by using the combined system.

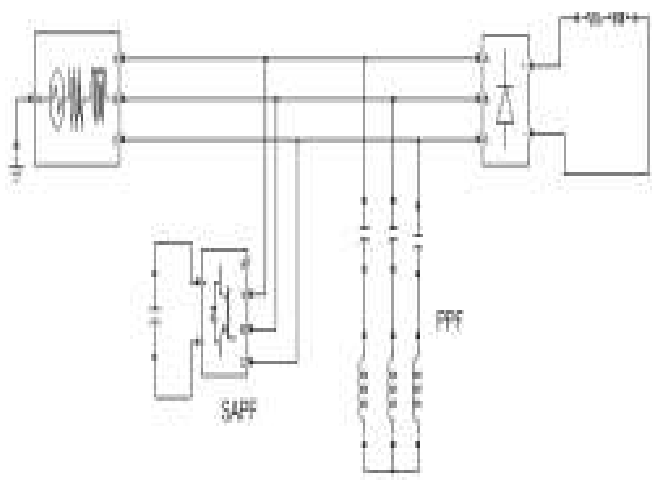

Figure. 1 Combination of shunt active filter and passive filter

The main circuit of the active filter is the PWM inverter using IGBT. The PWM inverter has a dc capacitance of $2000 \mu \mathrm{F}$.

\section{SHUNT ACTIVE POWER FILTER}

\section{A. Control Circuit of Shunt Active Filter}

The simulation block for control circuit of shunt active filter is shown in Fig.3. The three-phase reference supply currents are calculated by indirect current control technique. The PI-controllers outputs are connected to the phase currents and phase current outputs are connected to the firing pulse generator and given to the APF to produce the compensating current. 


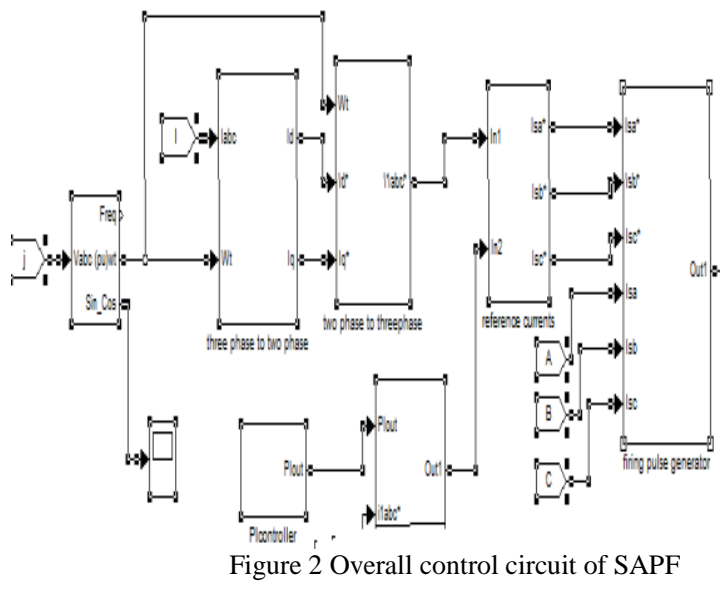

\section{B. Reference current calculation}

The simulation diagram for three-phase reference supply current calculation is shown in Fig.3. The input of the reference current is load current. The load current is combination of the harmonic current and fundamental current.

\section{Improved generalised integrator controller}

An improved PI-controller is used here to increase the performance of harmonic suppression. PI-controller is used to reduce the transient voltage errors between the filter current harmonic current. Here controller function is tuned to reduce particular harmonic. The structure of the improved controller is shown in Fig.4

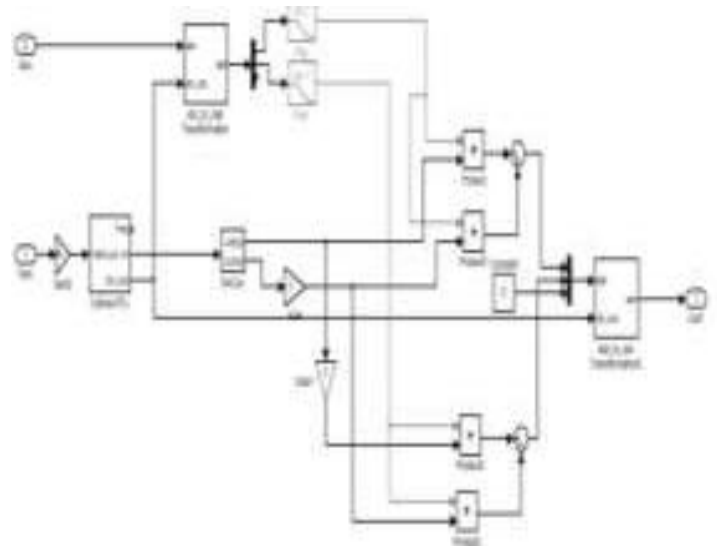

Figure 3. Reference current calculation

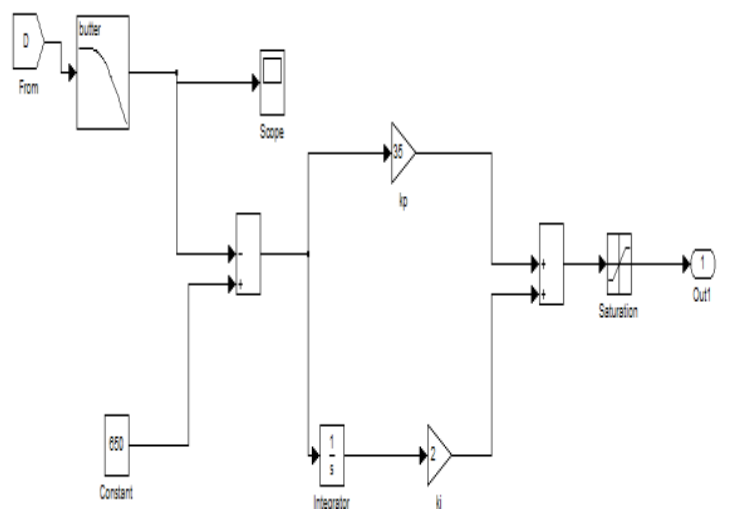

Figure 4 PI-controller using indirect current control technique.

\section{DSP HARDWARE AND CONTROL ALGORITHM}

In this section, the details of hardware interfacing with DSP system and basic equations of control algorithm are given.

\section{A. Description of DSP System Hardware}

Fig. 5 shows the DSP system hardware of the AF. The DSP system consists of a TSM320C31 digital signal processor, eight channels of 12 bit analog to digital converter (ADC), eight channels of 12-bit digital to analog converter (DAC), three hardware interrupts and three timer interrupts. The DSP system is serially interfaced to an IBM-PC. In PC the control algorithm is developed in C language and converted in assembly language codes using optimizing compiler. These assembly language codes are down loaded into the DSP board through serial port. The three-phase supply voltages and and dc bus voltage of the $\mathrm{AF}$ are input signals to the DSP board through its ADC interface. The dc bus voltage of the AF is sensed using an isolation amplifier (AD202) and scaled to feed to ADC channel. The synchronization of ac mains with the control algorithm in DSP system is obtained using one digital signal (hardware interrupt). This signal is generated using comparators and logic gates over the three-phase ac supply voltages. The three-phase ac supply voltages result in six zero crossing signals at 60 of intervals. Therefore, the digital signal continuously interrupts the DSP system at 60 time intervals of frequency of ac supply system. Using four analog signals and one hardware interrupt signal, the control algorithm of the AF is implemented in real time. The control algorithm of the AF generates three-phase reference supply currents. The three-phase reference supply currents and are input signals to DAC's of DSP. The outputs of DAC's are fed to a carrier wave PWM current controller. In PWM current controller the error signals of the reference, and and sensed and supply currents (sensed using LEM hall-effect curret sensors) are compared with a carrier signals resulting in gating pulses for the IGBT's of the AF.

\section{B. Basic Equations of Control Algorithm of the AF}

The three-phase reference supply currents are computed using three-phase supply voltages and dc bus voltage of the AF. These reference supply currents consist of two components, one in-phase and another in quadrature with the supply voltages.

The amplitude of (I*spd) in-phase component of reference supply currents is computed using PI controller over the average value of dc bus voltage (vdc) of the AF and its reference counterpart Comparison of average and reference values of dc bus voltage of the $\mathrm{AF}$ results in a voltage error, which is expressed as, at th sampling instant

$$
\mathrm{V}_{\mathrm{dcl}}(\mathrm{n})=\mathrm{V}_{\mathrm{dc}} *(\mathrm{n})-\mathrm{V}_{\mathrm{dc}}(\mathrm{n})
$$

The error signal, $\operatorname{vdcl}(\mathrm{n})$, is processed in PI controller and output $\mathrm{y} 0(\mathrm{n})$ at $\mathrm{n}$ th sampling instant is expressed as

$$
\mathrm{y}_{0}(\mathrm{n})=\mathrm{y}_{0}(\mathrm{n}-1)+\mathrm{K}_{\mathrm{pdc}}\left(\mathrm{V}_{\mathrm{dcl}}(\mathrm{n})-\mathrm{V}_{\mathrm{dcl}}(\mathrm{n}-1)\right)
$$




$$
+\mathrm{k}_{\mathrm{idc}} \mathrm{V}_{\mathrm{dcl}}(\mathrm{n})(2)
$$

Where and are proportional and integral gains of the dc bus voltage PI controller. The quantities, and

are the output of the voltage controller and voltage error, respectively, at nth sampling instant. The output of PI controller is taken as amplitude of in-phase component of the reference supply currents. Three-phase in-phase components of the reference supply currents are computed using their amplitude and in-phase unit current vectors derived in-phase with the supply voltages.

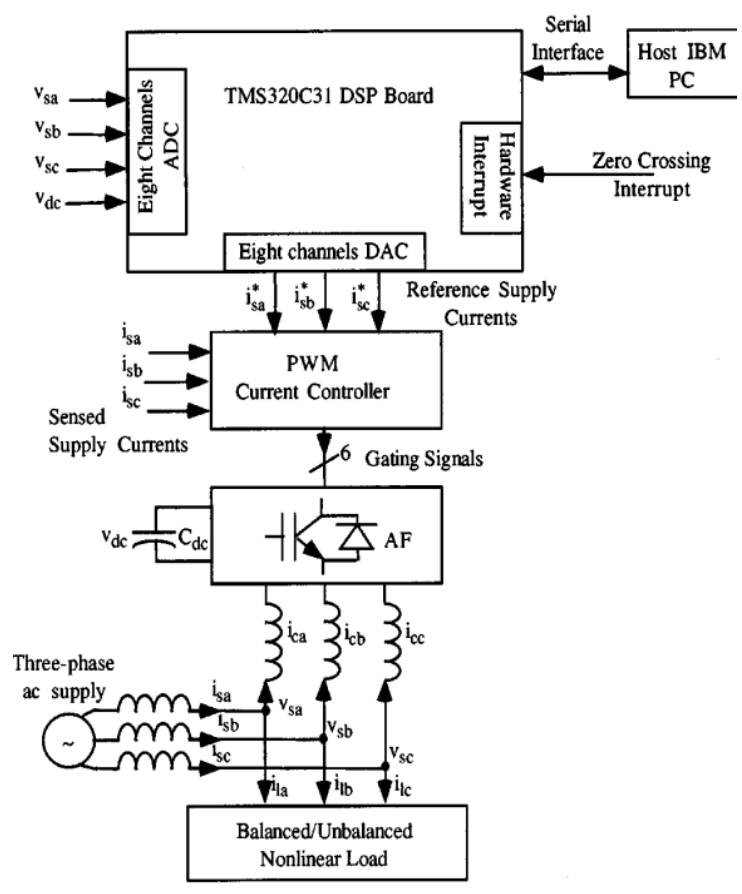

Figure 5. Digital signal processing (DSP) system hardware of the hybrid active filter.

\section{SIMULATION RESULTS}

The simulation results are compared with the control method of passive power filter (APF).

\section{A. Results for active power filter}

The simulation diagram of the ppf shown in Fig.6. The diagram consists of the source, non-linear load.

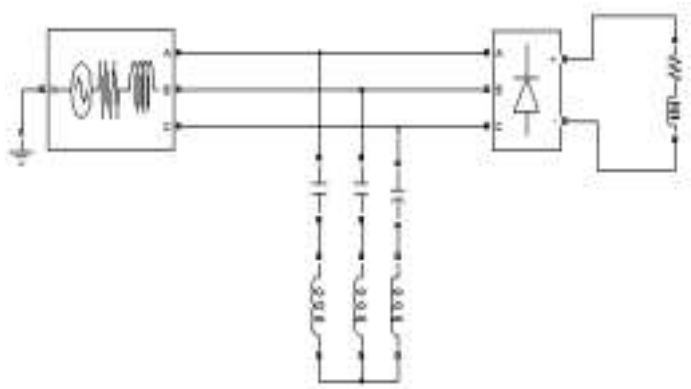

Figure 6. Simulation diagram with ppf

Fig.7 shows the waveform of supply current before compensation. It consist of fundamental current aswell-as the harmonic current due to the non-linear load.

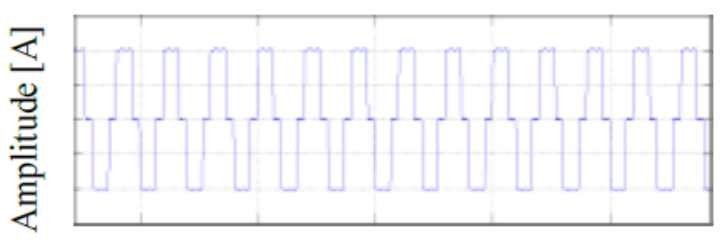

Time(s)

Figure 7. Supply current w waveform before compensation

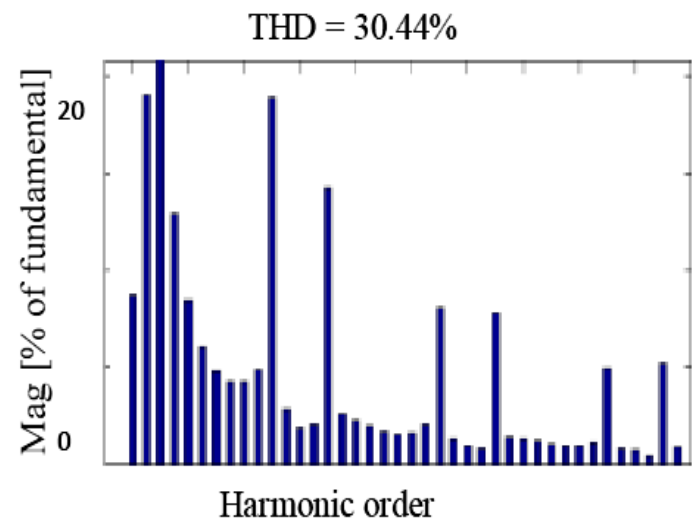

Figure 8. Spectrum analysis of supply current-before compensation.

Fig. 8 shows the spectrum analysis of supply current before compensation. The total harmonic distortion of the supply current is $64.25 \%$ Fig. 9 shows the waveform of supply current after compensation. It consists of fundamental current only. The harmonic current present in the supply current is eliminated by using the active filter.

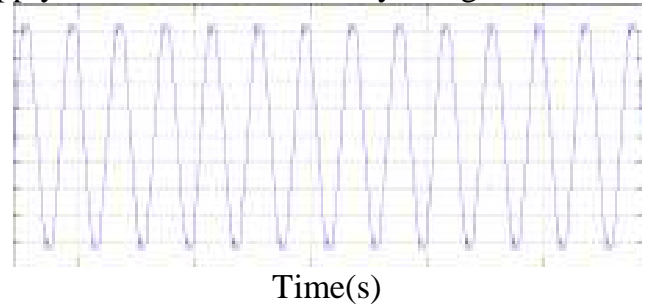

Figure 9. Supply current waveform -after compensation using PPf

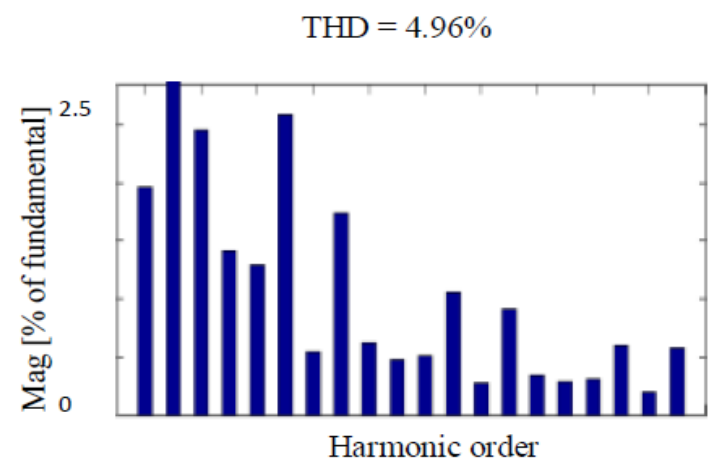

Figure 10. Spectrum analysis of supply current-after compensation using PPF

\section{B. Results for shunt active power filter}

The simulation diagram with APF is shown in Fig.11. The diagram consists of the source, non-linear load shunt active filter and its control circuit. 
Fig.12 shows the waveform of supply current after compensation. It consists of fundamental current only, the harmonic current present in the supply current is eliminated by using APF.

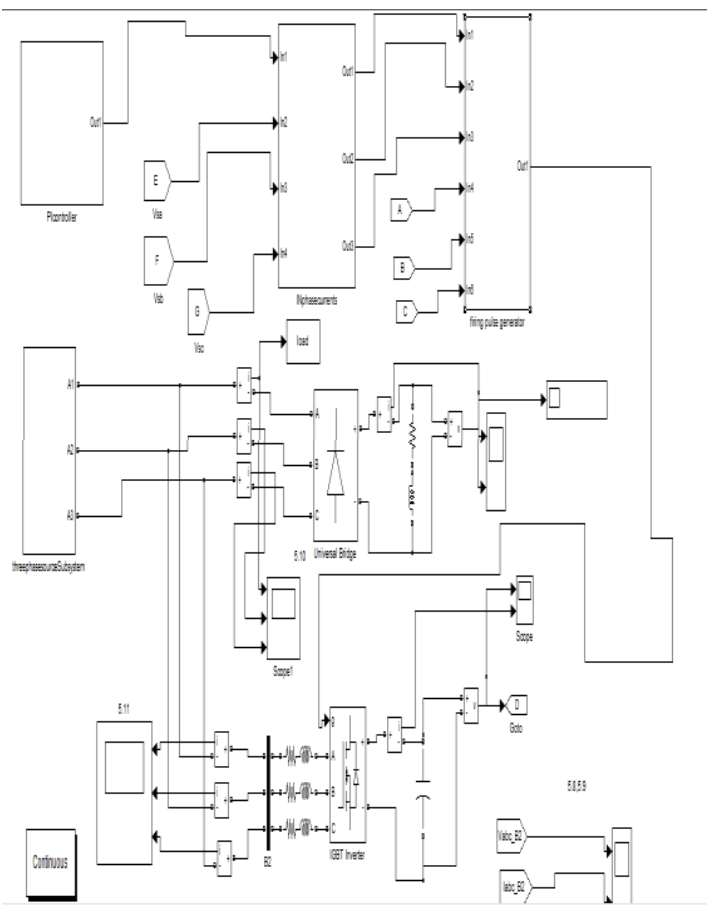

Figure 11. Simulation diagram with APF

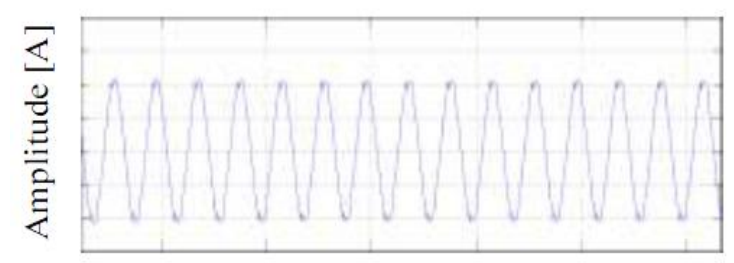

Time(s)

Figure 12. The supply current waveform after compensation using APF

Fig.13. shows the spectrum analysis of supply current after compensation. The total harmonic distortion of the supply current is reduced to $4.85 \%$ from $30.44 \%$

$\mathrm{THD}=4.85 \%$

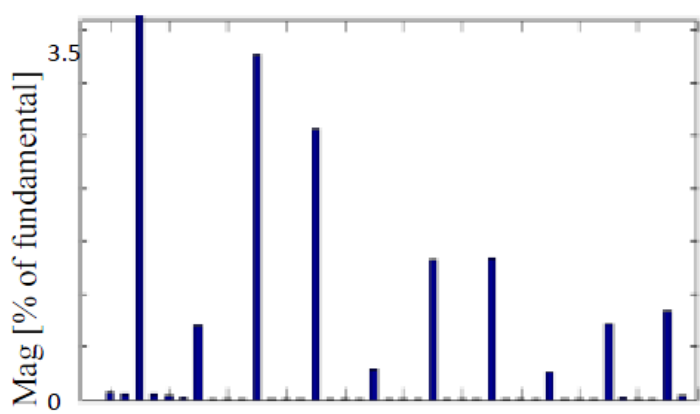

Harmonic order

Figure 13. Spectrum analysis of supply current after compensation using APF.

\section{RESULT FOR COMBINATION OF SHUNT ACTIVE POWER FILTER AND PASSIVE POWER FILTER}

The simulation diagram with shunt active power filter and passive power filter in Fig.14 The diagram consists of the source, non-linear loads, passive filter, shunt active power filter and its control circuit.

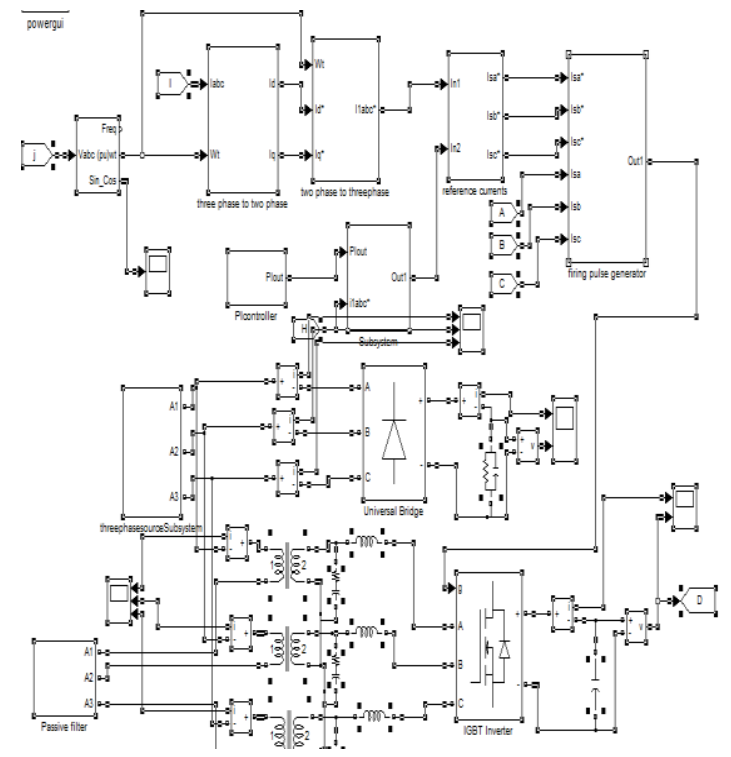

Figure 14. Simulation diagram with APF and PPF

Fig. 15 shows the waveform of supply current after compensation. The waveform is more sinusoidal when compared to other two techniques.

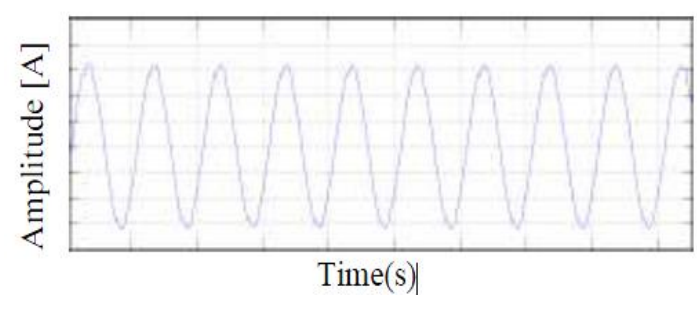

Figure 15. Shows the spectrum analysis of supply current after compensation using SAPF and PPF

Fig 16 shows the spectrum analysis of supply current after compensation. The total harmonic distortion of the supply current is reduced to $1.95 \%$ from $30.44 \%$ 
$\mathrm{THD}=1.95 \%$

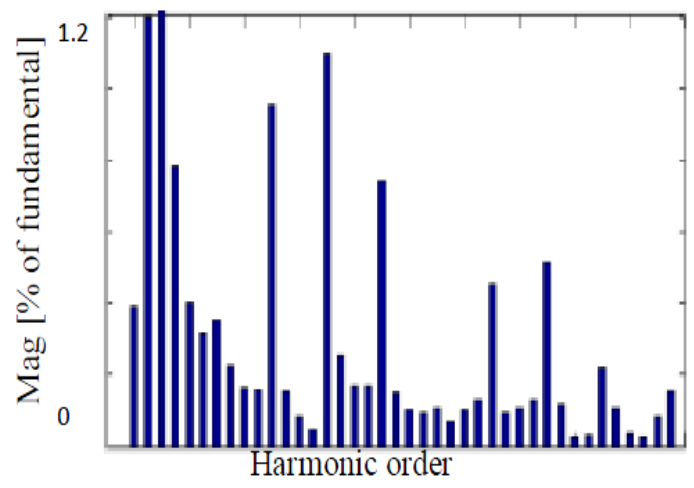

Figure 16. Spectrum analysis of supply current- after compensation using SAPF and PPF

\section{COMPARISION OF RESULTS}

Table 1. Comparison of $\%$ of harmonics

\begin{tabular}{|c|c|c|c|}
\hline \multirow{2}{*}{$\begin{array}{c}\text { Harmonic } \\
\text { order }\end{array}$} & \multicolumn{3}{|c|}{ \% of harmonics } \\
\cline { 2 - 4 } & $\begin{array}{c}\text { Before } \\
\text { Compensation }\end{array}$ & SAPF & $\begin{array}{c}\text { SAPF } \\
+ \\
\text { PPF }\end{array}$ \\
\hline $3^{\text {th }}$ & 4.79 & 0.70 & 0.35 \\
\hline $5^{\text {th }}$ & 18.91 & 3.28 & 0.96 \\
\hline $7^{\text {th }}$ & 14.24 & 2.56 & 1.10 \\
\hline $9^{\text {th }}$ & 1.16 & 0.89 & 0.74 \\
\hline $11^{\text {th }}$ & 1.66 & 1.33 & 0.11 \\
\hline $13^{\text {th }}$ & 7.75 & 1.34 & 0.45 \\
\hline
\end{tabular}

Table 2. Comparison of $\%$ of THD

\begin{tabular}{|c|c|}
\hline SYSTEM & $\%$ of THD \\
\hline Before compensation & 30.44 \\
\hline Passive Power Filter & 4.96 \\
\hline Shunt Active Power Filter & 4.85 \\
\hline $\begin{array}{c}\text { Combination of Shunt Active } \\
\text { ower Filter and Passive power } \\
\text { Filter }\end{array}$ & 1.95 \\
\hline
\end{tabular}

\section{CONCLUSION}

By using of the different non linear loads in the power system applications lot of voltage drops at the supply power stations, so the power quality of the different semiconductor devices are reduces and damages, so economical problems are occurs. By using this new control algorithm in power system applications, using three phase hybrid shunt active power filter almost the harmonic currents are eliminated at the supply, and maintains the power factor unity. This technique is applies in real-time control applications using DSPTMSLF2407, poor power quality, harmonics are eliminated, then overall cost is reduced and it maintains good power quality. From this paper by using MATLAB we can prove ,the THD at supply is reduced to $10 \%$ from $64.3 \%$ by using three phase shunt active filter(APF) and proper PI controllers. By using this technique it reduces the harmonics at supply as per IEEE standards.

\section{REFERENCES}

[1] L. Gyugyi and E. C. Strycula, "Active AC power Filters" in Proc.IEEE-IAS Annu. Meeting Record, 1976 , pp. 529-535.

[2] T. J. E. Miller, Reactive Power Control in Electric Systems Toronto,Ont., Canada: Wiley, 1982.

[3] J. F. Tremayne, "Impedance and phase balancing of main-frequency induction furnaces," Proc. Inst Elec Eng. B, pt. B, vol. 130, no. 3, pp.161-170, May 1983.

[4] J. Arrillaga, D. A. Bradley, and P. S. Bodger, Power System Harmonics.Chichester, U.K.: Willey, 1985.

[5] H. L. Jou, "Performance comparison of the threephase active power filter algorithms," in Proc. Inst. Elect. Eng., Generation, Transm, Distrib.,vol. 142, Nov. 1995, pp. 646-652.

[6] J.W. Dixon, J. J. Garcia, and L. Moran, "Control system for three-phase active power filter which simultaneously compensates power-factor and unbalanced loads," IEEE Trans. Ind. Electron., vol. 42, pp. 636-641,Dec. 1995.

[7] B. Singh, K. Al-Haddad, and A. Chandra, "A new control approach to three-phase active filter for Harmonics and reactive power compensation,"IEEE Trans. Power Syst., vol. 13, pp. 133-138, Feb. 1998.

[8] D. A. Paice, Power Electronic Converter HarmonicsMultipulse Methods for Clean Power New York: IEEE Press, 1996. 